\begin{tabular}{|c|c|}
\hline \multirow{3}{*}{ 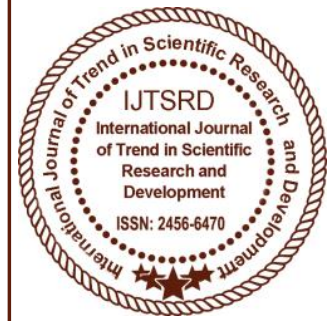 } & $\begin{array}{l}\text { International Journal of Trend in Scientific } \\
\text { Research and Development (IJTSRD) }\end{array}$ \\
\hline & UGC Approved International Open Access Journal \\
\hline & ISSN No: 2456 - 6470 | www.ijtsrd.com | Volume - 1 | Issue - 5 \\
\hline
\end{tabular}

\title{
Improving Properties of Concrete by Adding Pozzolonic Material such as, Silica Fumes and Ground Glass Blast Furnace Slag in India
}

\author{
Mohd Ismail Wani \\ Department of Civil Engineering Al-Falah University \\ Dhauj, Faridabad,Haryana
}

\author{
Mr. Zeshan Khan \\ Assistant Professor, Department of Civil Engineering \\ Al-Falah University Dhauj, Faridabad,Haryana
}

\section{ABSTRACT}

The aim of the study was to evaluate the performance of high performance concrete (HPC) containing supplementary cementitious materials in both binary and ternary systems. Concretes were prepared to have a slump value between $60-90 \mathrm{~mm}$ at a constant water binder ratio of 0.30 . Thetest variables included the type and the amount supplementary cementitious materials (SCMs) such as Silica fume, class F fly ash (FA) and Ground granulated blast furnace slag (GGBS). Portland cement was replaced with fly ash up to $40 \%$, silica fume up to $15 \%$ and GGBS up to a level of $70 \%$. The physical properties were assessed from compressive strength and transport properties (air permeability and sorptivity), whilst the durability characteristics were investigated in terms of carbonation, chloride migration, chloride diffusion, electrical resistivity and salt scaling resistance. The hydration properties of cement pastes containing SCMs have been investigated in order to understand the behavior of HPC. For Hydration properties, cement pastes were prepared in two series (A and B). Mixes of series A had a fixed water binder ratio of 0.30 with super plasticizer, whereas the water binder ratios of series $\mathrm{B}$ were equivalent to the standard consistencies. The results confirmed that silica fume performed better than other SCMs for strength development and bulk resistivity. In terms of resistivity of concrete, the best performance was obtained for $15 \% \mathrm{SF}$ concrete. When $7.5 \% \mathrm{SF}$ was used in $40 \%$ FA and $50 \%$ GGBS concrete, the resistivity was less $15 \% \mathrm{SF}$ concrete. The ternary mixes containing GGBS/FA and SF performed best amongst all mixes to resist chloride diffusion. The mix containing fly ash showed favourable permeation results. All ternary combinations can be considered to have resulted in high performance concretes with excellent durable properties. The maximum carbonation depth observed for concrete containing $40 \% \mathrm{FA}$ and $7.5 \% \mathrm{SF}$ was about $5 \mathrm{~mm}$, which is less than the cover of reinforced steel bars to cause corrosion. The non steady state migration coefficients 'of concretes containing different types of SCMs were significantly lower than the controlled concretes. The coefficient was minimum for concrete containing $15 \%$ SF. The scaled mass for $40 \% \mathrm{FA}$ concrete was the maximum among all mixes. For concrete containing was maximum among all the mixes. For concretes containing GGBS, there was no significant change in scaled mass, when compared to control concretes. However, the use of $15 \%$ SF was found to reduce the scaled mass. The use of $7.5 \% \mathrm{SF}$ in $40 \% \mathrm{FA}$ and $50 \%$ GGBS concrete was found to reduce the scaled mass. The $\mathrm{x}$-ray diffraction data showed that with the addition of high volume FA, GGBS and SF the peak intensity of $\mathrm{Ca}(\mathrm{OH}) 2$ was retarded and quartz peaks appeared in the paste containing FA denoting a certain amount of crystalline silica in FA. This was more pronounced at later age. The combination of $40 \%$ FA and $7.5 \%$ SF showed the highest consumption of $\mathrm{Ca}(\mathrm{OH}) 2$. Thermo gravi-metry data confirms the 
International Journal of Trend in Scientific Research and Development (IJTSRD) ISSN: 2456-6470

addition of SCMs in cement resulted in the formation of decreased amount of $\mathrm{Ca}(\mathrm{OH}) 2$ in the hydration products considerably at later age when compared to early age. Although the addition of high volumes of SCMs decreased the compressive strength of cement pastes at early age, the use of $15 \%$ SF improved the strength. However from the cost point of view, it is suggested that a combination of $40 \% \mathrm{FA}$ and $7.5 \% \mathrm{SF}$ or $50 \%$ GGBS and $7.5 \%$ SF can be beneficially used to improve the hydration properties and compressive strength of cement pastes.

Keywords: GGBS, FA, SilicaFume, HPC

\subsection{INTRODUCTION}

The properties of concrete are significantly influenced by the properties of cement paste. Therefore, it was necessary to investigate properties of the cement paste. Moreover, the cement paste is the matrix material for the concrete composite and it will be difficult to understand the behaviour of a composite without first understanding the matrix phase. In addition, the use of various supplementary cementitious materials (SCMs) such as FA (class F), GGBS and SF are reported to modify the hydration properties of cement paste. In this paper, details of the investigations 1 and 2 on the influence of various SCMs on the hydration properties are presented and discussed.

\subsection{PROPORTIONS}

The final mix proportions were arrived at after having done many trials so as to have a slump between 60-90 $\mathrm{mm}$ at a constant water-binder ratio $(\mathrm{w} / \mathrm{b})$ of 0.30 , coarse aggregate content of $1150 \mathrm{~kg} / \mathrm{m} 3$ and a constant total binder content of $485 \mathrm{~kg} / \mathrm{m} 3$. The slump was adjusted by adding different dosages of the SP. This final dosage of superplasticiser for constant slump (between $60 \mathrm{~mm}$ to $90 \mathrm{~mm}$ ) was achieved after having a number of trials (Table 1.1). Keeping in view the actual slump obtained, it can be concluded from the data shown that there is an increase in the trend of superplasticiser dosage with the incorporation of various SCMs, this is due to very high fineness of these materials.
Table 1.1: Superplasticiser dosage for mixes

\begin{tabular}{|c|c|c|}
\hline Mix ID & $\begin{array}{c}\text { Superplasticiser } \\
(\% \text { by mass of } \\
\text { OPC }\end{array}$ & $\begin{array}{c}\text { Actual slump } \\
(\mathbf{m m}) \\
\text { obtained }\end{array}$ \\
\hline HP-CC & 1.10 & 65 \\
\hline HP-SF7.5 & 1.35 & 60 \\
\hline HP-SF15 & 1.75 & 75 \\
\hline HP-BS50 & 1.75 & 80 \\
\hline HP-BS70 & 3.00 & 70 \\
\hline HP-SF+BS50 & 2.50 & 85 \\
\hline HP-FA20 & 1.75 & 85 \\
\hline HP-FA40 & 1.75 & 85 \\
\hline HP-SF+FA20 & 1.75 & 90 \\
\hline HP-SF+FA40 & 2.25 & 80 \\
\hline
\end{tabular}

\subsection{COMPRESSIVE \\ STRENGTH DEVELOPMENT}

The compressive strength development of cement pastes containing high volumes of different SCMs for Series A and B are reported in Table 1.2. It can be seen that as expected for both the series, the increase in compressive strength was positively related to the age for all the specimens. The incorporation of high volumes of FA and GGBS in the cement paste mixes produced a lower strength value at the early age but at later ages, the strengths either greater or comparable to the control mix. The improvement in the compressive strength at later ages is mainly due to the pozzolanic reaction. The compressive strength of paste mix containing $15 \% \mathrm{SF}$ was greater than that of the FA and GGBS paste mixes at all ages. This is due to the micro filler effect of SF in addition to its pozzolanic properties.

\section{Table 1.2: Compressive strength development for various mixes}

\begin{tabular}{|l|l|l|l|l|}
\hline \multirow{2}{*}{ Mix ID } & \multicolumn{4}{|c|}{ Compressive strenght (Mpa) } \\
\hline A-CC & 3 days & $\mathbf{7}$ days & $\mathbf{2 8}$ days & 9 days \\
\hline A-FA40 & 29.57 & 62.76 & 67.76 & 83.74 \\
\hline A-BS50 & 34.79 & 35.08 & 64.25 & 72.88 \\
\hline A-BS70 & 32.7 & 48.67 & 70.03 & 74.02 \\
\hline A-SF15 & 49.71 & 66.52 & 68.78 & 88.98 \\
\hline A-FA40+SF7.5 & 32.08 & 42.95 & 71.04 & 78 \\
\hline A-BS50+SF7.5 & 37.88 & 52.69 & 76.84 & 99.9 \\
\hline B-CC & 47.6 & 52.9 & 81.68 & 85.76 \\
\hline B-FA40 & 34.02 & 39.02 & 53.76 & 80.4 \\
\hline B-BS50 & 22.66 & 58.4 & 77.66 & 84.52 \\
\hline
\end{tabular}


International Journal of Trend in Scientific Research and Development (IJTSRD) ISSN: 2456-6470

\begin{tabular}{|l|l|l|l|l|}
\hline B-BS70 & 26.78 & 41.3 & 60.52 & 73.08 \\
\hline B-SF15 & 43.68 & 53.8 & 76.28 & 90.4 \\
\hline B-FA40+SF7.5 & 29.98 & 41.04 & 67.44 & 84.8 \\
\hline B-BS50+SF7.5 & 42.4 & 46.48 & 72.3 & 85.32 \\
\hline
\end{tabular}

the reference mix $(100 \%$ OPC) are reported in Table 4.5. Figure 4.1 shows that $\mathrm{SF}$ at the replacement level of $7.5 \%$ performed consistently better than OPC in terms of strength development at all the test ages, similar to other published results (Byung et.al.,2002; Khatri and Sirivivatnanon, 1995). The incorporation When compared to the $40 \% \mathrm{Fa}$ and $50 \%$ GGBS cement paste mixes, the use of $7.5 \%$ Sf along with either $40 \%$ FA or $50 \%$ GGBS improved the compressive strenght both at early and later age. The improvement was more significant in cement paste mixes containing $40 \% \mathrm{FA}$ and $7.5 \% \mathrm{SF}$. Literature on the use of various waste materials, such as FA, GGBS and SF as supplementary cementitious materials also show marked improvement in the compressive strength of mixes (Lewis et al., 2003; Sellevold and Radjy, 1983; Andriolo and Saqaraboza, 1986).

\subsection{WORKABILITY AND AIR CONTENT}

The results for slump and air content are reported in Table 1.3. It can be seen from this table that the measured slump was within the target range of 60-90 $\mathrm{mm}$. Air content was also very close to the assumed values which was considered while calculating contents of different ingredients following the method as already discussed in previous sections.

Table 1.3: Workability (Slump) and Air Content

\begin{tabular}{|l|l|l|}
\hline Mix ID & Slump $(\mathrm{mm})$ & Air content (\%) \\
\hline HP-CC & 65 & 3.5 \\
\hline HP-SF7.5 & 60 & 3 \\
\hline HP-SF15 & 75 & 2.5 \\
\hline HP-BS50 & 80 & 2.75 \\
\hline HP-BS70 & 70 & 2.5 \\
\hline HP-SF+BS50 & 85 & 2.75 \\
\hline HP-FA20 & 85 & 3 \\
\hline HP-FA40 & 85 & 2.5 \\
\hline HP-SF+FA20 & 90 & 2.5 \\
\hline HP-SF+FA40 & 80 & 2.5 \\
\hline
\end{tabular}

\subsection{COMPRESSIVE STRENGTH}

The compressive strength results are reported in Table 1.4. These results are presented in Figs. 4.1 and 4.2 and the changes in compressive strength in relation to

of $15 \%$ SF exhibited the best compressive strength results at both 28 and 91 days, but at both 3 and 7 days, the compressive strength was lower than both the PC mix and the binary mix containing $7.5 \% \mathrm{SF}$. Table 4.5 demonstrates that the enhancement in strength (that is the rate of strength development) continued for both SF7.5 and SF15 mixes up to 28 days, beyond which the rate of strength development decreased.

Figure 1.1 also shows the strength development of different GGBS mixes. The 50\% GGBS mix exhibited almost the same strength as that of PC at both 28 and 91 days, but at early ages ( 3 and 7 days), the latter performed better. This can be seen clearly in Table 4.5 , where the strength of HP-BS50 in relation to the control was about $100 \%$ at both 28 and 91 days. The addition of $7.5 \%$ SF to the $50 \%$ GGBS mix did not result in any improvement in early-age strength, but at both 28 days and 91 days, this had a beneficial effect, with the strength exceeding that of the control mix (Table 1.5). When the GGBS content was increased from $50 \%$ to $70 \%$, the strength decreased at all ages.

Table 1.4: Compressive strength of various concrete mixes

\begin{tabular}{|l|l|l|l|l|}
\hline \multirow{2}{*}{ Mix ID } & \multicolumn{4}{|l|}{ Compressive strength (MPa) } \\
\cline { 2 - 5 } & 3 days & 7 days & 28 days & 91 days \\
\hline HP-CC & 57.2 & 66.3 & 81.4 & 92.6 \\
\hline HP-SF7.5 & 58.4 & 72.7 & 95.5 & 101.8 \\
\hline HP-SF15 & 49.6 & 65.5 & 98.3 & 107 \\
\hline HP-BS50 & 42.3 & 63.1 & 80.3 & 89.6 \\
\hline HP-BS70 & 21.8 & 40.9 & 60.5 & 72.1 \\
\hline HP-SF+BS50 & 34.6 & 59.3 & 86.1 & 93.8 \\
\hline HP-FA20 & 46.1 & 53.8 & 64.7 & 81 \\
\hline HP-FA40 & 28.3 & 35.8 & 47.2 & 70.2 \\
\hline HP-SF+FA20 & 34.9 & 47.2 & 76.8 & 90.3 \\
\hline HP-SF+FA40 & 26.3 & 38.1 & 61.9 & 82.1 \\
\hline
\end{tabular}


International Journal of Trend in Scientific Research and Development (IJTSRD) ISSN: 2456-6470

Table 1.5: Strength of mixes relative to the control mix at each test age

\begin{tabular}{|l|l|l|l|l|}
\hline Mix ID & Compressive strength at different ages relative to control mix (\%) \\
\hline & 3 days & 7 days & 28 days & 91 days \\
\hline HP-CC & 100 & 100 & 100 & 100 \\
\hline HP-SF7.5 & 102.1 & 109.7 & 117.3 & 109.9 \\
\hline HP-SF15 & 86.7 & 98.8 & 120.8 & 115.6 \\
\hline HP-BS50 & 74.0 & 95.2 & 98.6 & 96.8 \\
\hline HP-BS 70 & 38.1 & 61.7 & 74.3 & 77.9 \\
\hline HP-SF+BS50 & 60.5 & 89.4 & 105.8 & 101.3 \\
\hline HP-FA20 & 80.6 & 81.1 & 79.5 & 87.5 \\
\hline HP-FA40 & 49.5 & 54.0 & 58.0 & 75.8 \\
\hline HP-SF+FA20 & 61.0 & 71.2 & 94.3 & 97.5 \\
\hline HP-SF+FA40 & 46.0 & 57.5 & 76.0 & 88.7 \\
\hline
\end{tabular}

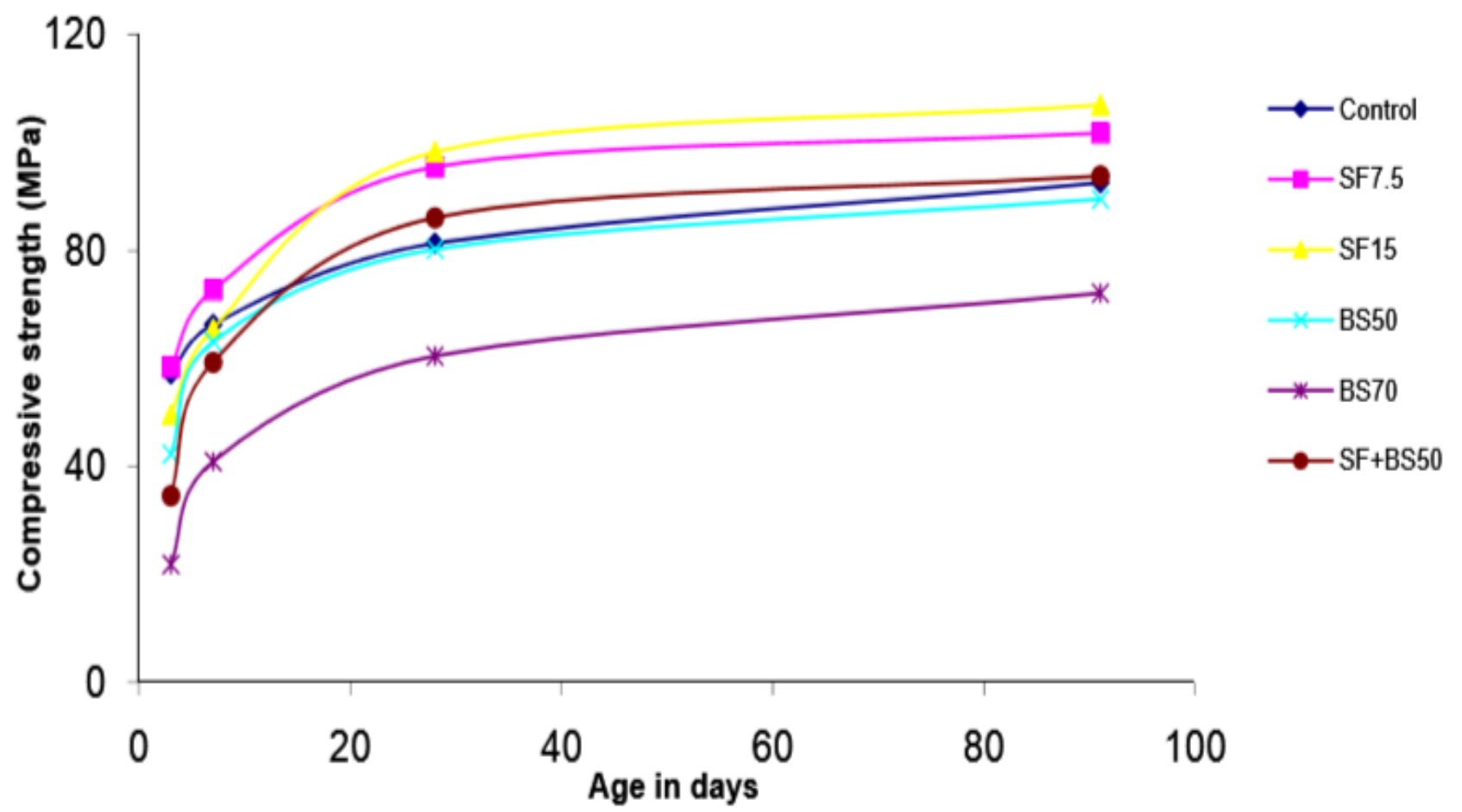

Fig 1.1 Compressive strength development of binary and ternary mixes containing SF and GGBS

Compressive strength enhancement in concrete mixes containing SF is possibly because of chemical and physical effects contributed by SF. Chemical effect is largely because of the pozzolanic reactions between calcium hydroxide $(\mathrm{CH})$ obtained from the hydration of OPC and the amorphous silica present in SF to produce secondary calcium-silicate-hydrates $(\mathrm{C}-\mathrm{S}-\mathrm{H})$. The physical (filler) effect is due to the dense packing of the concrete because of SF fine particles. SF particles fill the spaces between the cement grains. (ACI Committee 234, 1995).

The particle size and surface area also increase the rate of reactivity. SF has very fine particle size $(0.1-0.3 \mu \mathrm{m})$ compared to that of GGBS $(10-20 \mu \mathrm{m})$. Hence, the rate of pozzolanic reaction of SF is noticeably higher than those of GGBS. Hence, SF starts to pay much contribution to the strength enhancement at an early stage in hydration compared to GGBS. However, it is clear from the test results that sufficient quantities of $\mathrm{CH}$ should 
be available before getting the benefit of SF. This was particularly the case with $15 \%$ of SF. As both SF and GGBS were competing for $\mathrm{CH}$, the addition of $7.5 \%$ SF did not contribute to additional compressive strength.

Figure 1.2 shows the compressive strength at different ages with different FA replacement levels. The strength development of the concrete at both the FA replacement levels was consistently lower than that of the control mix at all the ages. Both Fig 1.2 and Table 1.5 demonstrate that not only both FA mixes had a lower strength compared to the control mix, but also an increase in FA content further reduced the strength. As all the mixes were cast with the same $\mathrm{w} / \mathrm{b}$ and the slump was similar, the reduction in the strength of FA mixes is considered to be the result of slower pozzolanic reaction of the FA in these mixes. Table 1.5 shows that the addition of $7.5 \% \mathrm{SF}$ enhanced the compressive strength at all ages beyond the first week. In the case of GGBS mix, this was observed only from 28 days. Therefore, it can be concluded that the addition of $7.5 \%$ SF is more beneficial to the FA mixes than to the GGBS mixes.

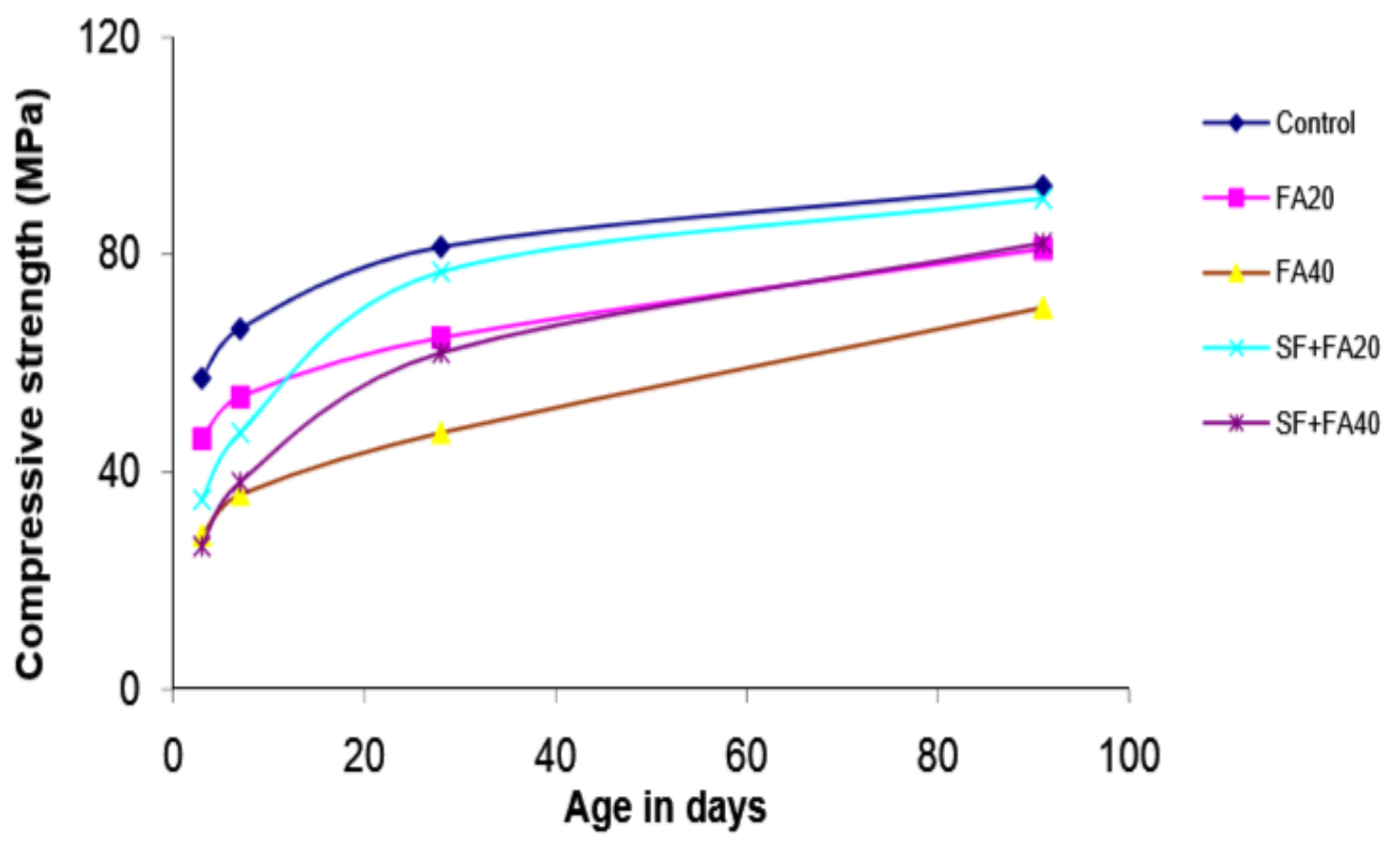

Fig 1.2 Compressive strength development of binary and ternary mixes containing FA

The compressive strength of ternary mixes of FA and GGBS were observed to be greater than their binary mixes. The use of SF reduces the porosity of the interfacial transition zone (ITZ) in concrete due to their ability to fill the pores in ITZ with the silica particles and reduces the amount of calcium hydoxide $(\mathrm{CH})$ due to its high pozzolanic reactivity (Roy, 1989). The densification of the interfacial transition zone allows for efficient load transfer between the cement mortar and the coarse aggregate, contributing to the strength of the concrete (Maage, 1986).

The increase in strength of ternary mixes could be attributed to the improvement in the bond between the hydrated cement matrix and the aggregate (Maage, 1986). This is due to the conversion of calcium hydroxide, which tends to form on the surface of aggregate particles to calcium silicate hydrate. As the average particle size of SF is very small compared to those of other binder particles, it contributes to the grain refinement of the ternary mixes of FA and GGBS.

\subsection{ELECTRICAL RESISTIVITY}

The electrical resistivity is an important concrete property that allows the evaluation of the access facility of aggressive agents before the corrosion process starts. It also estimates the velocity of the same process after it begun. The results of bulk resistivity for various mixes are reported in Table 1.6. All the binary and ternary mixes showed an increase in bulk resistivity from 3 to 13 times greater than the control OPC mix. Thepores, in the mixes with SCM, are generally discontinuous due to the denser microstructure (Lawler et al., 2007). As stated earlier, 
there could be two effects due to the incorporation of SCMs, viz. physical densification of the microstructure and pozzolanic reaction leading to the formation of secondary CSH. Both these could lead to an increase in resistivity. Amongst the SCM blends, the highest resistivity was obtained for SF15 and the lowest for BS50. Generally the addition of SF increased the resistivity of both FA and GGBS mixes, as reported by other researchers (Song et al., 2007; Hooton et al., 1997).

\section{Table 1.6: Bulk resistivity and chloride diffusion results of various mixes}

\begin{tabular}{|c|c|c|}
\hline Mix ID & $\begin{array}{c}\text { Bulk Resistivity } \\
\text { Pbulk } \\
(\Omega-m)\end{array}$ & $\begin{array}{c}\text { Chloride diffusion } \\
\text { coefficient } \times 10^{-12} \mathbf{~ m}^{2} / \mathrm{s}\end{array}$ \\
\hline CC & 155.23 & 3.112 \\
\hline SF7.5 & 965.28 & 0.869 \\
\hline SF15 & 2046.40 & 0.739 \\
\hline BS50 & 464.87 & 0.206 \\
\hline BS70 & 738.88 & 1.012 \\
\hline SF+BS50 & 1173.41 & 0.801 \\
\hline FA20 & 1023.08 & 1.227 \\
\hline FA40 & 715.95 & 1.548 \\
\hline SF+FA20 & 1198.50 & 0.712 \\
\hline SF+FA40 & 1061.91 & 0.536 \\
\hline
\end{tabular}

The pores in the mixes with SCMs are generally discontinuous due to the denser microstructure. In addition, the pores may also become blocked because of the products achieved after hydration of the binders. Therefore, greater value of resistivity was observed in case of these mixes. As the flow of electrical current through hydrating cement paste is electrolytic, that is, mainly due to the flow of ions through the pore spaces, its resistivity is an indirect measurement of porosity and, hence, the diffusivity of concrete ( $\mathrm{Gu}$ et al., 1995). In reinforced concrete structures at the onset of corrosion of the rebars, the corrosion current and, hence, the corrosion rate is influenced by the electrical resistivity of the concrete. The high electrical resistivity of concrete containing SCMs would cause the overall resistivity of the HPC to increase and, hence, a lower rate ofcorrosion after the breakdown of passivity. This is considered to be due to the pore refinement due to either chloride binding or the formation of chloro-aluminates, or the combination of both these. The increase in resistivity of HPC with SCMs can also be because of ionic concentration. The electrical resistivity of concrete is mainly related to ionic mobility in the pore solution, which is a function of the ionic concentration. The incorporation of supplementary cementitious materials (SCMs), especially silica fume reduces the ionic concentration of the pore solution due to the binding of ions ( $\mathrm{Na}, \mathrm{K}, \mathrm{Cl}$, etc.) in the cementitious matrix. Therefore, resistivity tests have been criticized for various shortcomings such as giving favorable results to concrete incorporating SCMs (e.g. silica fume). Therefore, other parameters (chloride diffusion and migration) were also measured in this research that can better quantify the pore structure of HPC produced from binary and ternary binders. Diffusion of chloride ions into concrete is directly dependent on the continuity and refinement of the pore structure, while resistivity of concrete is mainly governed by ionic concentration in the pore solution, as explained earlier. Thereby, it is inappropriate to use resistivity/conductivity as an indicator for ions penetrability (i.e. implicating the characteristics of the pore structure) in concrete made with binders incorporating SCMs.

\subsection{CARBONATION}

The carbonation depth of concrete containing different types of high volumes of SCMs is shown in Fig. 1.3. These values are reported in Table 1.7. It can be seen that the carbonation depth was maximum for concrete containing $40 \%$ FA. At early ages, the effect of the incorporation of $15 \%$ SF on carbonation depth was found to be similar to that of the control concrete. However, from 28 days onwards the carbonation depth of $15 \%$ SF concrete was found to be less than that of the control concrete. This is in good agreement with the findings of other researchers (Khan and Lynsdale, 2002; Byfors, 1985; Maage, 1986). For instance, Byfors (1985) investigated the carbonation of concrete containing FA and SF blended cement and found that the incorporation of $10-20 \% \mathrm{SF}$ has no effect on carbonation as compared to the control concrete, whilst $15-40 \%$ FA exhibited higher rate of carbonation. 
International Journal of Trend in Scientific Research and Development (IJTSRD) ISSN: 2456-6470

Table 1.7: Depth of carbonation of various mixes

\begin{tabular}{|l|l|l|l|l|l|}
\hline \multirow{2}{*}{ Mix ID } & \multicolumn{6}{|c|}{ Depth of carbonation $(\mathrm{mm})$} \\
\cline { 2 - 7 } & $\begin{array}{l}\mathbf{7} \\
\text { days }\end{array}$ & $\begin{array}{l}\mathbf{1 4} \\
\text { days }\end{array}$ & $\begin{array}{l}\mathbf{2 8} \\
\text { days }\end{array}$ & $\begin{array}{l}\mathbf{5 6} \\
\text { days }\end{array}$ & $\begin{array}{l}\mathbf{1 1 2} \\
\text { days }\end{array}$ \\
\hline CC & 2.16 & 2.92 & 3.27 & 5.11 & 6.11 \\
\hline FA40 & 5.58 & 7.72 & 7.9 & 10.19 & 11.43 \\
\hline BS50 & 3.07 & 3.92 & 4.59 & 6.02 & 8.77 \\
\hline BS70 & 7.19 & 7.75 & 8.49 & 8.57 & 9.99 \\
\hline SF15 & 2.58 & 3.25 & 2.81 & 3.12 & 4.12 \\
\hline FA40+SF7.5 & 4.21 & 4.56 & 4.71 & 4.89 & 4.99 \\
\hline BS50+SF7.5 & 2 & 3.03 & 4.11 & 5.14 & 6.78 \\
\hline
\end{tabular}

The carbonation depth of concrete with 50\% GGBS was lower than the $40 \%$ FA concrete. The content of calcium hydroxide $(\mathrm{CH})$ and carbon dioxide penetration rate are the two key factors controlling the carbonation rate of concrete. GGBS is generally much more active than the FA. HPC with GGBS having lower $\mathrm{CH}$ content and denser matrix showed a better carbonation resistance than HPC with FA. However, $70 \%$ GGBS showed an increase in the carbonation depth. This could be due to the fact that the replacement level was too high. The maximum carbonation depth observed for (high volume FA) concrete containing $40 \% \mathrm{FA}$ and $7.5 \% \mathrm{SF}$ was about $5 \mathrm{~mm}$, which is less than the cover of reinforcing steel bars to cause the corrosion. Therefore, it can be said that if this combination is used, there is a less risk of corrosion due to carbonation.

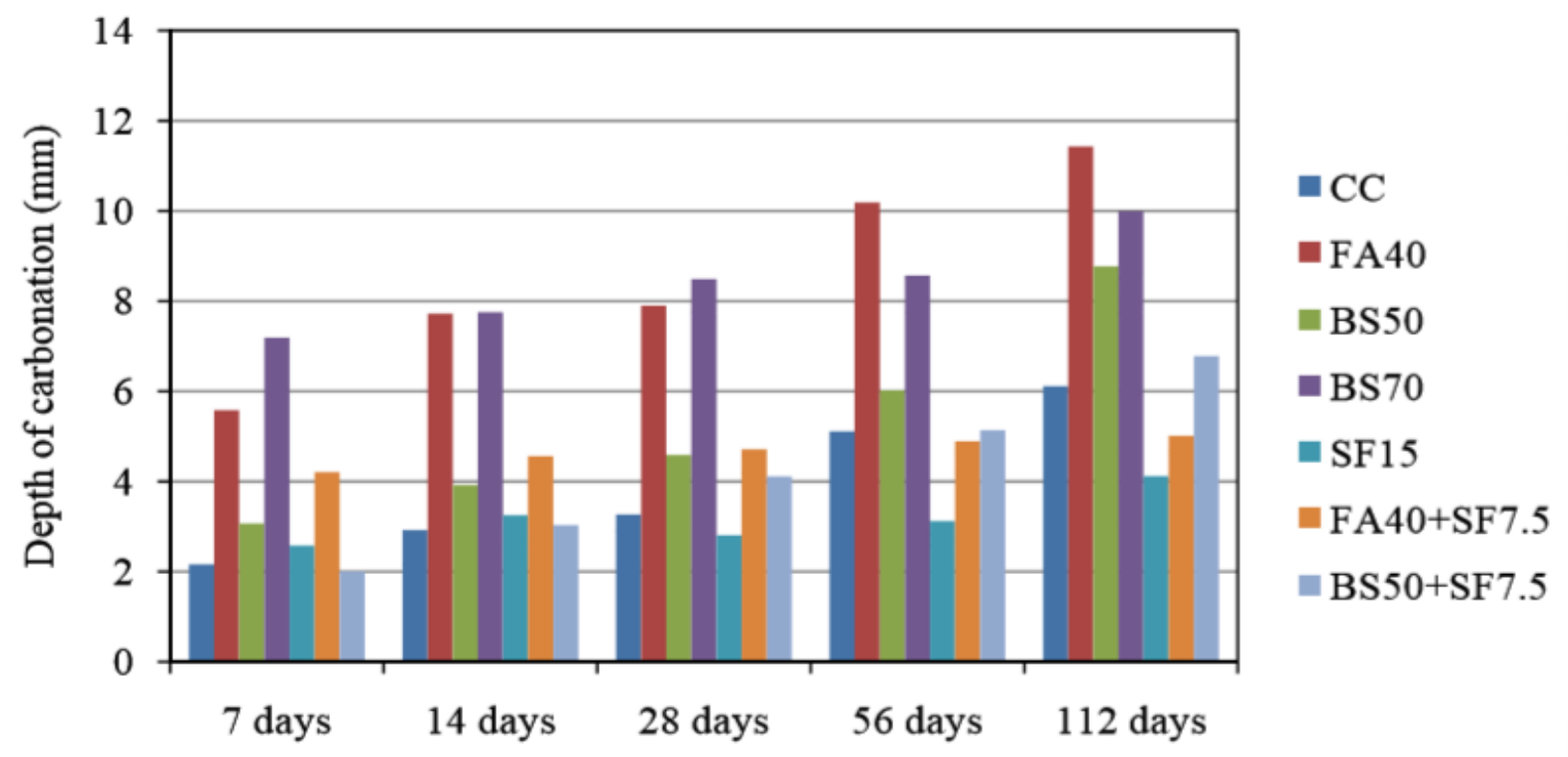

Fig 1.3 Carbonation Depth

\subsection{CHLORIDE MIGRATION}

The test results of chloride migration are reported in Table 1.8 and these results are shown in Fig 1.4. It can be seen that the non-steady state migration coefficient of concrete containing different types of SCMs were significantly lower than the control concrete. The coefficient was minimumfor concrete containing $15 \% \mathrm{SF}$. This could be due to the densification of the matrix brought about by the pozzolanic reactions of SF, which blocks the pores.

Table 1.8: Chloride migration and salt scaling results of various mixes

\begin{tabular}{|l|l|l|}
\hline Mix ID & $\begin{array}{l}\text { Chloride migration coefficient } \\
\times 10^{-12} \mathrm{~m}^{2} / \mathrm{s}\end{array}$ & Scaled mass in gram \\
\hline CC & 7.882 & 45.51 \\
\hline FA40 & 2.442 & 315.22 \\
\hline BS50 & 1.186 & 76.4 \\
\hline
\end{tabular}


International Journal of Trend in Scientific Research and Development (IJTSRD) ISSN: 2456-6470

\begin{tabular}{|l|l|l|}
\hline BS70 & 1.442 & 68.16 \\
\hline SF15 & 0.382 & 25.47 \\
\hline FA40+SF7.5 & 1.072 & 105.21 \\
\hline BS50+SF7.5 & 0.915 & 26.1 \\
\hline
\end{tabular}

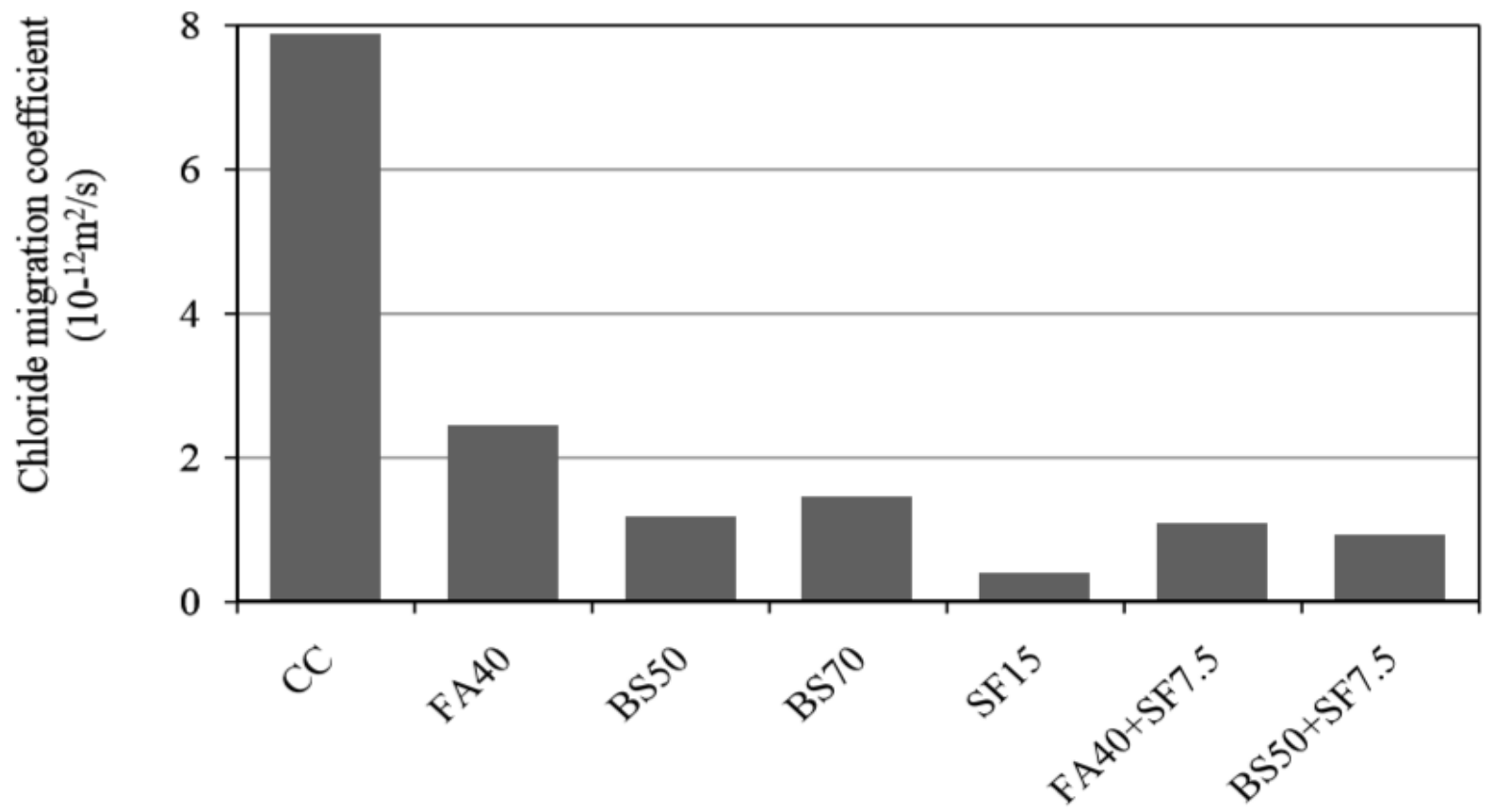

Fig 1.4 Chloride migration

Another interesting thing that can be observed in this figure is that compared to the FA, GGBS was relatively more effective in reducing the chloride migration coefficient. This could be due to the secondary chemical reaction of GGBS that contributes to make the microstructure denser.However, $50 \%$ GGBS seems to be optimum as beyond this content there was no improvement in the resistance to chloride migration. The concrete containing $7.5 \% \mathrm{SF}$ in combination with $40 \% \mathrm{FA}$ and $50 \%$ GGBS also performed better than that of the control mix and $40 \%$ FA concrete.

\subsection{SALT-SCALING}

The scaled mass of various concrete measured after 400 cycles is reported in Table 1.8. Although according to the CDF test procedure (Setzer et al., 1996), the scaled mass should be measured after every 4 cycles up to 28 cycles, this was not possible in this case. This is because the concretes were HPC and no scaling was observed even after 100 cycles. It can be seen that the scaled mass for $40 \%$ FA concrete was the maximum among all the mixes.
Numerous laboratory test data ( $\mathrm{Gu}$ et al., 1995 ;Bilodeau et al., 1994) in accordance with ASTM C 672 have indicated that air-entrained concretes incorporating high volumes of FA often perform inadequately when exposed to freezing and thawing cycles in the presence of de-icing salts. Whereas, there are several reported cases of concrete structures adding considerable FA contents that have performed positively when exposed to de-icing salts in the field (Mehta and Monteiro, 2005). It is believed that ASTM C 672 is an excessively severe test for determining the de-icing salt scaling resistance of high volume FA concrete in actual field application. Until now, there is no noticeable for this discrepancy between laboratory observation and field experience.

It can be observed that for concrete containing GGBS (both $50 \%$ and $70 \%$ ), there was no significant change in the scaled mass, when compared to the control concrete. However, the use of $15 \%$ SF was found to reduce the scaled mass. It can also be observed that concrete containing $40 \% \mathrm{FA}+7.5 \% \mathrm{SF}$ and $50 \%$ GGBS $+7.5 \%$ SF reduced the scaled mass. The findings are in agreement with that of the other researchers (Bilodeau and Malhotra, 1992; Jacobsen et al., 1991; Valenza and scherer, 2007; McCabe, 
1999), which show that, SCMs usually do not increase the scaling potential if all the factors (e.g., adequate air entrainment, low $\mathrm{w} / \mathrm{b}$ and proper finishing and curing practices) are satisfied.

\subsection{CONCLUSIONS}

On the basis of the results obtained from this research work, the following conclusions have been drawn:

$>$ TG data confirms that the addition of SCMs in cement resulted in the formation of decreased amount of $\mathrm{Ca}(\mathrm{OH}) 2$ in the hydration products at all ages. However, this was more significant at later age (91 days) when compared to the early age ( 3 days). This may be attributed to the dilution effect and to the consumption of $\mathrm{Ca}(\mathrm{OH}) 2$ by pozzolanic reaction.

$>$ The incorporation of high volumes of FA and GGBS in the cement paste mixes produced a lower strength value at the early age. However, at later ages, the strength was either greater or comparable to the control specimen. Although, the compressive strength of cement paste containing $15 \%$ SF was greater than that of the FA and GGBS concrete at all ages, from cost point of view, it can be suggested that a combination of $40 \%$ FA and $7.5 \%$ SF or $50 \%$ GGBS and $7.5 \%$ SF can be beneficially used to improve the hydration properties and compressive strength of cement paste.

$>$ With the w/b kept constant at 0.3 , the compressive strength was detrimentally affected by the replacement of OPC with both FA and GGBS at all ages up to 91 days. However, the compressive strength increased at all ages due to the use of SF at $7.5 \%$ replacement levels. There was a decrease in compressive strength at early ages when the SF content was increased from $7.5 \%$ to $15 \%$. It was possible to enhance the long-term compressive strength of both FA and GGBS mixes with the addition of $7.5 \%$ of SF, but there was a decrease in compressive strength at early ages.

$>$ There was a decrease in air permeability with age for all the mixes. No advantage was observed in adding SF to both the control mix (OPC only) and binary mixes from the point of view of the air impermeability, except mixes SF15 and SF+FA20. The binary mixes with $40 \%$ FA showed a dramatic reduction in air permeability at 44 days, followed by $20 \%$ FA mix at 44 days. The control mix exhibited the lowest air permeability values at later ages, marginally above the mix with $40 \% \mathrm{FA}$ at the same age. This means that HPCs with low air permeability could be obtained without the addition of any supplementary cementitious materials. However, these mixes may perform adequately only where air permeability is the criterion affecting its durability.

There was a decrease in sorptivity (water absorption) with age for all the mixes. SF was less pronounced in improving the sorptivity at 44 as well as 91 days. The $50 \%$ GGBS, both with and without SF, improved the water absorption at 44 and 91 days. Similarly, the $20 \%$ FA with and without SF improved the water absorption at 91 days. SF improved the GGBS concrete more than FA concrete. That is, in the case of sorptivity (water absorption), there was benefit with the addition of $20 \%$ FA and $50 \%$ GGBS compared to the control concrete. However, the improvement to sorptivity with the addition of SF was marginal.

$>$ All the mixes with cement replacement materials showed at least three times greater resistance to chloride diffusion than the control mix. Amongst all the binary mixes, SF mixes showed the best performance in improving the chloride resistance. Even the ternary mixes, achieved by the inclusion of SF in FA and GGBS concretes, exhibited increase in the resistance to chloride diffusion.

The type and content of binders had almost the same effect on penetration parameter and bulk resistivity as their effect on the resistance to chloride diffusion. Amongst the SCM blends, the highest resistivity was obtained for SF15 and the lowest for BS50. Generally the addition of SF increased the resistivity of FA and GGBS mixes.

The carbonation depth was maximum for concrete containing $40 \%$ FA. Although at early ages, the effect of the incorporation of $15 \%$ SF on carbonation depth was found to be similar to that of the control concrete; from 28 days onwards the carbonation depth of $15 \%$ SF concrete was found to be less than that of the control concrete. The maximum carbonation depth observed for (high volume FA) concrete containing $40 \% \mathrm{FA}$ and $7.5 \%$ SF was about $5 \mathrm{~mm}$, which is less than the cover of reinforcing steel bars to cause corrosion.

The resistivity of concrete containing $40 \%$ FA and GGBS (both $50 \%$ and $70 \%$ ) was higher than that of the control concrete. The best performance was obtained for $15 \%$ SF concrete. When $7.5 \%$ SF was used in $40 \%$ FA and $50 \%$ GGBS concrete, the resistivity was less than that of the $15 \% \mathrm{SF}$ 
concrete. However, in both cases, this was greater than the control concrete.

$>$ The scaled mass for $40 \%$ FA concrete was the maximum among all the mixes. For concrete containing GGBS, there was no significant change in the scaled mass, when compared to the control concrete. However, the use of $15 \%$ SF was found to reduce the scaled mass. The use of $7.5 \% \mathrm{SF}$ in $40 \%$ FA and $50 \%$ GGBS concrete was found to reduce the scaled mass.

$>$ The results of the tests carried out on the HPC concretes containing SF, FA and GGBS in large volumes clearly illustrated that some mix combinations are superior to others for different properties presented in this research work. Clearly this would mean that HPCs for different exposure conditions could be designed and produced with a combination of different cementitious materials and the exact choice of these combinations should be based on the physical properties relevant to the durability and performance expected from the HPC.

$>$ All the mixes with cement replacement materials showed at least three times greater resistance to chloride diffusion than the control mix. Amongst all the binary mixes, SF mixes showed the best performance in improving the chloride resistance. Even the ternary mixes, achieved by the inclusion of SF in FA and GGBS concretes, exhibited increase in the resistance to chloride diffusion.

$>$ The non-steady state migration coefficients of concrete containing different type of SCMs were significantly lower than the control concrete. The coefficient was minimum for concrete containing $15 \%$ SF.

These conclusions would highlight that HPCs for different exposures require different types of blends in order to obtain the best performance. As a consequence, mixes need to be designed for different transport properties for different exposure conditions.

\subsection{RECOMMENDATIONS}

Although this research has indicated the limits in which OPC can be replaced with SCMs to beneficially produce durable HPC without detrimentally affecting the strength of concrete, the following further research is recommended in order to broaden the use of SCMs in HPC.
In this study the SCMs considered are taken each from one source. However, as the properties of SCM vary from source to source, further research should be carried out to evaluate the effects of SCMs from different sources on the performance of HPC.

$>$ There is a need to investigate the influence of tortuosity and interfacial transition zone on air permeability of HPC especially FA and GGBS concretes containing $7.5 \%$ silica fume at 91 days.

$>$ In spite of the nonlinear behaviour of concrete, an estimate of modulus of elasticity is necessary for computing the design stresses under load in simple elements, and moments and deflections in complicated structures. In addition to this, the modulus of elasticity also affects the serviceability and structural performance of reinforced structures. Therefore, there is a need to investigate the elastic modulus of HPC containing high volumes of SCMs.

$>$ Due to the relatively more complicated morphology of SCMs when compared to cement particles, the drying shrinkage mechanism of concrete containing SCMs could be different from that of concrete containing only OPC. Hence, a detailed study on the drying shrinkage properties is required.

$>$ Microscopy work should be done on the blended cement pastes. Microscopy will help showing the effect of binders on hydrated cement paste, interfacial transition zone and pore structure with direct micro- structural evidence.

\section{REFERENCES}

1) AASHTO T 277, Rapid determination of chloride permeability of concrete,Standard Specification for Transportation Materials and Methods of Sampling and Testing, Part 2: Test Methods. American Association of State Highway andTransportation Officials, 1989.

2) Abdun-nur, E.A., Fly ash in concrete-an evaluation, Highways Research Bulletin, 284, National Research Council, 1983, 138 pp.

3) Aitcin, P.C., "Cements of yesterday and today. Concrete of tomorrow", Cement \& Concrete Research Issue No. 9, Vol. 30, pp. 1349-1359, 2000.

4) Aïtcin, P.C. and Mehta, P.K., Effect of coarse aggregate type or mechanical properties of high strength concrete. ACI Materials Journal, American Concrete Institute, Detroit, Vol. 87, No. 2, pp. 103-107, 1990. 
5) Anon, Fly ash use as a concrete additive questioned by building inspectors, Engineers News-Record, 152, 12, 1954, pages. 22.

6) Arya, C. and Xu, Y., Effect of cement type on chloride binding and corrosion of steel in concrete, Cement and Concrete Research, Vol. 25, 1995, pp. 893-902.

7) ASTM Committee C-9/ C666-92, Test method for resistance to rapid freezing and thawing, Annual Book of ASTM Standards, vol. 04.02, 1983.

8) ASTM C672 / C672 M-03, "Standard Test Method for Scaling Resistance of Concrete Surface Exposed to Deicing Chemicals," Annual Book of ASTM Standards 2004, Volume 04.02, ASTM International, West Conshohocken, PA, pp. 353-355, 2004.

9) Atis, C.D., Accelerated carbonation and testing of concrete made with fly ash, Construction and Building Materials, Vol. 17, 2003, pp. 147-152.

10) Babu, K.G. and Ramakumar, V.S., Efficiency of GGBS in concrete, Cement and Concrete Research, Vol. 30(7), 2000, pp. 1031-1036.

11) Bakker, R.F.M., Permeability of blended cement concretes, SP-79, Vol.2, V.M.Malhotra, Ed., American Concrete Institute, Detroit, MI, 1983, pp.589-695.

12) Bamforth, P.B. "Concrete classifications for RC structures exposed to marine and other salt-laden environments". Proc. of 5 Int. Conf. on Structural Faults and Repair, Vol. 2, Edinburgh, pp.31-40, 1993.

13) Bamforth, P.B., An international review of chloride ingress into structural concrete, Contractor Report 359, Transport Research Laboratory, Edinburgh, 1997, 162 pp.

14) Basheer, L., Kropp, J. and Cleland, D.J., Assessment of the durability of concrete from its permeation properties: a review, Construction and Building Materials 15, 2001, pp. 93-103

15) Bloem, D.L. and Gaynor, R.D., Effects of aggregate properties on strength of concrete, Journal of American Concrete Institute, 60, October, 1963, pp. 1429-1455.

16) British Standards Institution, Guide to specifying concrete, BSI, London, BS 5328, Part $1,1990$.

17) British Standards Institution, Concrete - Part 1: Specification, performance, production and conformity, BSI, London, BS EN 206-1: 2000.
18) British Standards Institution, Testing Fresh Concrete: Slump Test, BSI, London, BS EN 12350: Part 2, 2000.

19) Byfors, K., Carbonation of concrete with silica fume and fly ash, Nordic Concrete Research, Oslo, Norway, 1985.

20) Byung, H.O., Soo, W.C., Bong, S.J. and Seung, Y.J., "Development of High Performance Concrete Having High Resistance to Chloride Penetration." Nuclear Engineering and Design, Vol. 212 (1), 2002, pp. 221-231.

21) Canadian Portland Cement Association, Design and control of concrete. Edition CPCA, Ottawa, 1991.

22) Carette, C.G., and Malhotra, V. M., "LongTerm strength Development of silica Fume Concrete", CANMET/ACI 4. International Conference on Fly Ash, silica Fume, Slag and Natural Pozzolans in Concrete, Istanbul. ACI SP132 Vol.2, ed. V.M. Malhotra, ACI, Detroit, pp.1017-1044.

23) Cordon, W.A., Freezing and thawing of concrete - mechanisams and control, ACI Monograph No. 3, Detroit, 1966, 99 pp. 